\title{
Characterizing the interactions between GPI-anchored alkaline phosphatases and membrane domains by AFM
}

\author{
Marie-Cécile Giocondi • Bastien Seantier • \\ Patrice Dosset • Pierre-Emmanuel Milhiet • \\ Christian Le Grimellec
}

Received: 25 September 2007 /Revised: 12 November 2007 / Accepted: 20 November 2007 / Published online: 6 December 2007

(C) Springer-Verlag 2007

\begin{abstract}
In plasma membranes, most glycosylphosphatidylinositol-anchored proteins (GPI proteins) would be associated with ordered microdomains enriched in sphingolipids and cholesterol. Debates on the composition and the nano- or mesoscales organization of these membrane domains are still opened. This complexity of biomembranes explains the use, in the recent years, of both model systems and atomic force microscopy (AFM) approaches to better characterize GPI proteins/membranes interactions. So far, the studies have mainly been focused on alkaline phosphatases of intestinal (BIAP) or placental (PLAP) origins reconstituted in model systems. The data show that GPI-anchored alkaline phosphatases (AP-GPI) molecules inserted in supported membranes can be easily imaged by AFM, in physiological buffer. They are generally observed in the most ordered domains of model membranes under phase separation, i.e. presenting both fluid and ordered domains. This direct access to the membrane structure at a mesoscopic scale allows establishing the GPI
\end{abstract}

M.-C. Giocondi · B. Seantier · P. Dosset - P.-E. Milhiet •

C. Le Grimellec

Institut National de la Santé et de la Recherche Médicale, Unité 554,

Montpellier, France

M.-C. Giocondi - B. Seantier · P. Dosset - P.-E. Milhiet •

C. Le Grimellec

Université de Montpellier,

Centre National de la Recherche Scientifique, UMR 5048,

Centre de Biochimie Structurale,

Montpellier, France

C. Le Grimellec $(\triangle)$

Nanostructures and Membrane Complexes,

Centre de Biochimie Structurale,

29 rue de Navacelles,

34090 Montpellier Cedex, France

e-mail: clg@cbs.cnrs.fr protein induced changes in microdomains size. It provides direct evidence for the temperature-dependent distribution of a GPI protein between fluid and ordered membrane domains. Origins of reported differences in the behavior of BIAP and PLAP are discussed. Finally, advantages and limits of AFM in the study of GPI proteins/membrane domains interactions are presented in this review.

Key words Alkaline phosphatases · Model systems . Supported bilayer Phase separation

\section{Introduction}

Glycosylphosphatidylinositol-anchored proteins (GPI proteins) are eukaryotic exoplasmic membrane proteins that play very diverse biological functions including hydrolytic enzyme activity, transmembrane signaling, intracellular sorting and cell adhesion interaction [32, 62, 66]. Besides these biological functions, GPI proteins such as alkaline phosphatases (AP-GPI), 5'-nucleotidase, dipeptidase, aminopeptidase $\mathrm{P}$, have been used primarily as markers of plasma membranes during their purification procedure $[6$, 28, 96]. Later, most of GPI proteins were found to be resistant to Triton X-100 solubilization at low temperature in kidney brush border membranes, whereas transmembrane enzymes were solubilized [44]. Similar observations were done on stably transfected MDCK strain II cells expressing the GPI human placental alkaline phosphatase (PLAP). The same experiments also revealed that the lipid composition of the low density, PLAP-enriched, Triton X-100 insoluble fraction had a molar ratio of glycerophospholipid to sphingolipid to cholesterol (Chl) of about 1:1:1 [11]. This ratio is close to the composition of the apical plasma membrane of renal [16, 60] and intestinal [7, 25, 33] 
epithelial cells. It is worth noting that because sphingolipids are essentially present on the outer plasma membrane leaflet, the GPI proteins should be initially localized in sphingolipids/Chl domains, with the glycerolipids occupying the inner membrane leaflet. Subsequently, detergent resistant plasma membrane fractions (DRMs) were isolated from a wide variety of eukaryotic cells [12]. This gave a new impulse to the hypothesis of the heterogeneous lateral organization of membrane constituents proposed in the mid 1970s to early 1980s [53, 71]. For epithelia, lateral heterogeneity was considered to account for the unusual physical state properties of intestinal [8] and renal [57] cells plasma membranes. For some time, DRMs were thought to correspond to microdomains present in the native plasma membrane [1]. Sphingolipids- and Chl-enriched microdomains were proposed to form "rafts" [85], a category of small (10-200 nm), heterogeneous, highly dynamic domains that compartmentalize cellular processes [74] and are involved in a variety of functions including signal transduction and membrane trafficking [27, 43]. Consequently, GPI proteins were promoted rafts markers. Like DRMs, rafts are expected to be in the liquid ordered phase $\left(l_{\mathrm{o}}\right)$, a phase characterized by ordered phospholipids chains. However, in contrast to the highly ordered $L_{\beta^{\prime}}$ gel phase, the lateral and rotational diffusion rates of $l_{\mathrm{o}}$ phase compare to those of the $L_{\alpha}$ fluid, liquid-disordered $\left(l_{\mathrm{d}}\right)$ phase [81, 93]. Interactions between $\mathrm{Chl}$ and other membrane lipid chains are determinant in $l_{\mathrm{o}}$ formation. Immiscibility of the different phases $\left(l_{\mathrm{o}}\right.$ vs $l_{\mathrm{d}}, L_{\beta^{\prime}}$ vs $l_{\mathrm{o}}$ or $\left.l_{\mathrm{d}}\right)$ would be responsible for the phase separation and the formation of lipid dependent microdomains in biomembranes. Natural sphingomyelin (SM) and glycosphingolipids are more saturated and contain longer acyl chains than glycerophospholipids [95]. This results in higher gel to fluid transition temperatures. For many of these sphingolipids, the upper end of the gel to fluid transition is above physiological temperature. This means that a fraction of the lipid is still in the gel phase at physiological temperature. Because $l_{\mathrm{o}}$ and $l_{\mathrm{d}}$ become miscible at a critical temperature above the main gel to fluid phase transition temperature [47], one expect $l_{\mathrm{o}}-$ $l_{\mathrm{d}}$ phase coalescence to occur at higher temperatures for $\mathrm{SM} /$ $\mathrm{Chl}$ than for glycerophospholipids/Chl microdomains [80].

It seems reasonable now to consider that DRMs should not be identified with rafts [61], whose lifetime and size limits remain a matter of debates $[42,48]$. Whereas there is now little doubt, if any, about the heterogeneous lateral organization of biomembranes, in situ characterization of microdomains depends on the highly preferential, if not exclusive, association of markers with a category of domains. How atomic force microscopy (AFM) can contribute to the understanding of a marker association with microdomains will be presented in this review. Choosing GPI-alkaline phosphatases as representative of raft-marker GPI proteins, we will discuss what kind of unique information AFM can provide and the actual limitations of the technique. We will also discuss the predictable consequences for biomembranes organization of the AFM findings on model systems.

\section{AFM detection of AP-GPI in model membranes}

Mammalian alkaline phosphatases (EC 3.1.3.1) are widely distributed enzymes that catalyze nonspecific hydrolysis of phosphate monoesters in an alkaline environment. They are expressed by different genes in intestine, in placenta and bones, and liver and kidneys [62]. They are highly polymorphic dimeric proteins made of homodimers, each monomer having a GPI anchor linked to the C-terminal group. X-ray resolved structure of PLAP indicates that the dimer adopts a prolate ellipsoid shape with a great axis of $\sim 10 \mathrm{~nm}$ parallel to the membrane surface and minor axis of $\sim 5 \mathrm{~nm}$ corresponding to the extramembranous height of the molecule [56]. The bovine intestinal alkaline phosphatase (BIAP) presents about $90 \%$ sequence similarity with PLAP and is made of two identical monomers containing 486 amino acids and one GPI anchor. The apparent molecular weight from electrophoresis determination is about $130 \mathrm{kDa}$ [78]. This size, associated with the possibility to purify reasonable amount of eukaryotic protein from a single source, makes AP-GPI attractive candidates for studying GPI-anchored proteins/model membrane domains interactions by AFM. One has to remind that, under favorable conditions, this technique allows to reach $\mathrm{a} \sim 1 \AA \AA$ vertical and $5 \AA$ Á lateral resolution on soft mater under liquid $[29,83]$.

Most of the available biomimetic systems like LangmuirBlodgett films (LB), supported lipid bilayers (SLBs), large (LUVs), and giant unilamellar vesicles (GUVs) have been used to better characterize the formation of in-plane lipiddependent microdomains and lipid/AP-GPI interactions in membranes [15, 17, 21, 52, 55, 67, 78].

Like other GPI proteins including acetylcholinesterase, GPI-murine B7-1 and B7-2 [76], variant surface glycoprotein (VSG) from Trypanosoma brucei, GPI-human decay accelerating factor [19, 70], and GPI-green fluorescent protein (GFP-GPI) [59], PLAP added to the medium spontaneously inserts into biomembranes [54]. Osseous plate AP-GPI and PLAP can also spontaneously insert into preformed liposomes $[15,54]$. Compared with reconstitution procedures, where the protein is added before or during the bilayer formation, this process presents the important advantage to insure an exclusive right side outside orientation of the APGPI at the external leaflet of the membrane.

In model systems, AFM allows to image lipid domains from the nano- to the microscopic scale, giving direct 
access to the mesoscopic scale where biomembrane microdomains essentially take place. Existence, shape, and size of lipid domains in LB films and SLBs are generally detected using difference in thickness and/or mechanical properties between immiscible phases [20, 26, 51, 69, 91]. Schematically, one expect the thickness and the lipid order parameter of a lipid bilayer to follow the sequence gel $>l_{\mathrm{o}}>l_{\mathrm{d}}$ [87]. An example of temperature-dependent existence of $\left(\mathrm{gel} / l_{\mathrm{o}}\right)-l_{\mathrm{d}}$ domains coexistence detected by height difference between phases is illustrated in Fig. 1. Figure 1 shows the evolution between room temperature and $50^{\circ} \mathrm{C}$ of the topography of a model raft, i.e. a model system whose lipid composition resembles that expected for those biomembranes lipid microdomains enriched in sphingolipids. Lighter protruding ordered domains were observed up to $35^{\circ} \mathrm{C}$ (Fig. 1a-c) but disappeared from $40^{\circ} \mathrm{C}$ (Fig. 1d-f), in accordance with the differential scanning calorimetry thermogram (Fig. 1g).

Direct AFM detection of the AP-GPI presence on SLBs can be obtained upon addition of BIAP in the buffer bathing preformed ordered-fluid phase separated bilayers $[40,68]$. This is illustrated in Fig. 2 for a SLB made of an equimolar mixture of dioleoylphosphatidylcholine (DOPC), a phosphatidylcholine bearing two monounsaturated C18:1 acyl chains in the fluid state at room temperature, and of dipalmitoylphosphatidylcholine (DPPC), a phosphatidylcholine with two saturated C16:0 acyl chains in the ordered (gel) state under the same condition. AFM allowed to image the progressive appearance of bright dots $\sim 12$ to $100 \mathrm{~nm}$ in diameter (Fig. 2b,c), essentially protruding from the surface of the lightest, i.e. the ordered DPPC-enriched membrane domains [67]. The minimal size of bright dots was compatible with structural data [56] and the time course of their visualization at the membrane surface agreed with previous work done on direct incorporation of AP-GPI into liposomes [15]. The presence of larger spots at the membrane surface also gave direct support for BIAP having a marked tendency to form clusters, a hypothesis formulated from indirect biochemical [13] and physicochemical [78] evidences. It is worth noting that pretreatment of BIAP with phosphatidylinositol-specific phospholipase $\mathrm{C}$ to remove the GPI anchor prevented the imaging of the protein at the SLBs surface. It indicated that SLB domains/GPI anchor hydrophobic interactions played an essential role in BIAP
Fig. 1 Temperature-dependent AFM imaging of model rafts. Supported bilayers made of POPC/SM/Chl (1:1:0.35 mol: mol) were imaged in phosphate buffered saline (PBS), $\mathrm{pH} 7.4$, between room temperature $\left(25^{\circ} \mathrm{C}\right)$ and $50^{\circ} \mathrm{C}$. Membrane ordered domains (gel $+l_{\mathrm{o}}$ phases) protruding from the fluid $\left(l_{\mathrm{d}}\right.$ phase) are no more observed at $40^{\circ} \mathrm{C} . \mathbf{a}, \mathbf{b}, \mathbf{c}, \mathbf{d}, \mathbf{e}$, and $\mathbf{f}$ correspond to height images of the same zone obtained at $25,30,35,40,45$, and $50^{\circ} \mathrm{C}$, respectively.

Bar:1 $\mu \mathrm{m}$. The vertical $\mathrm{z}$ color scale is $20 \mathrm{~nm}$. g Differential scanning calorimetry thermogram showing that the upper end of the thermogram is in agreement with AFM data
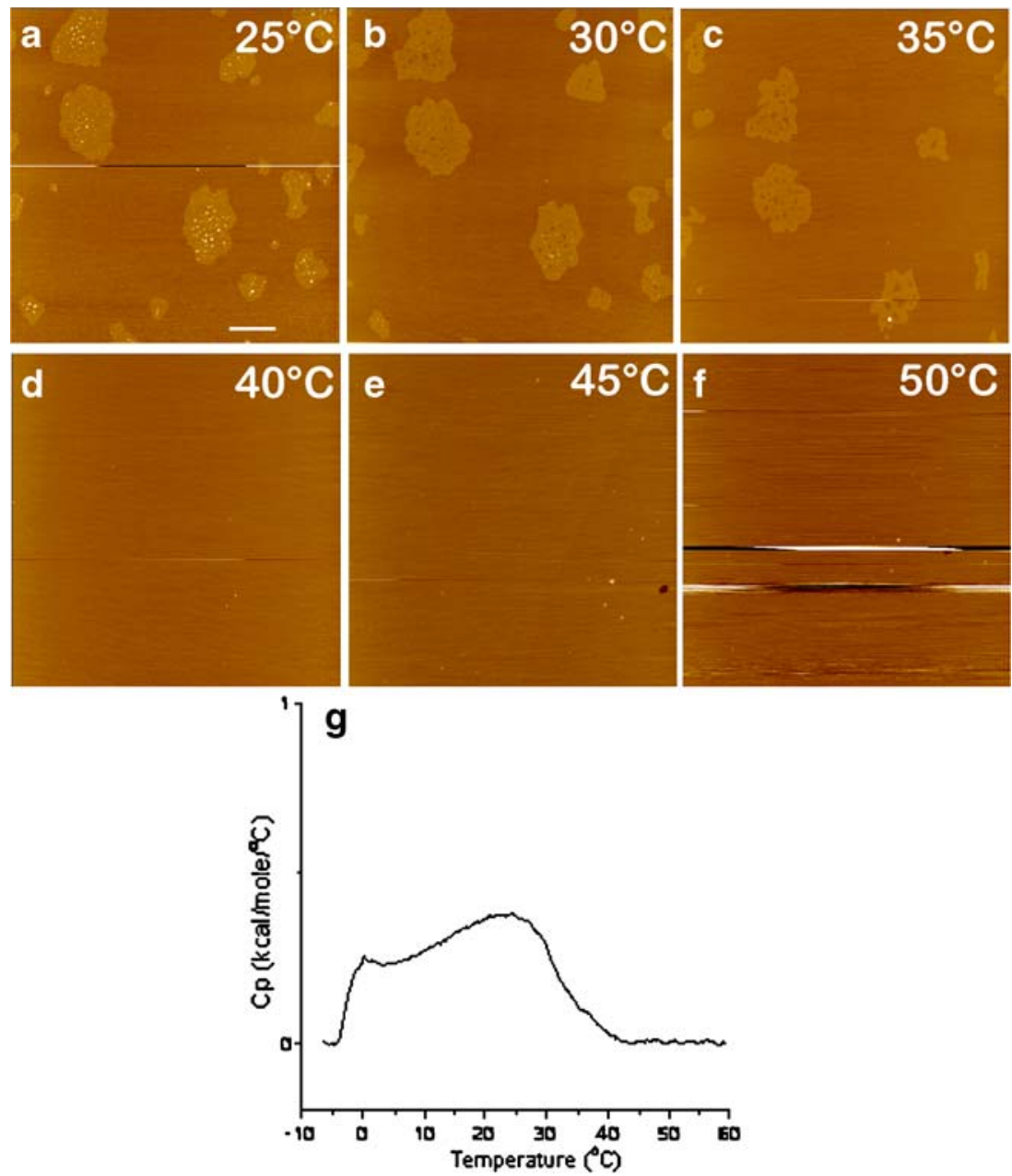


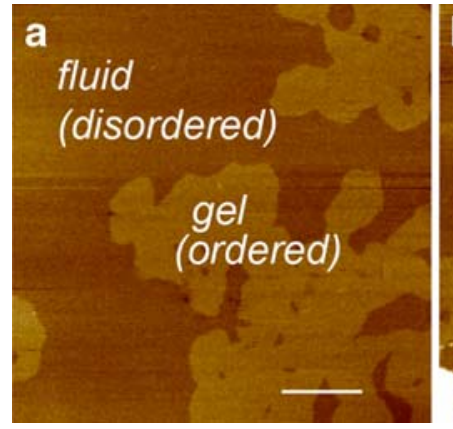

Fig. 2 Spontaneous time-dependent insertion of BIAP in DOPC/ DPPC supported bilayers. SLB were incubated, at room temperature, with purified BIAP and imaged by AFM as a function of time. a AFM height image before addition of BIAP; $\mathbf{b}$ AFM height image $45 \mathrm{~min}$ after BIAP addition; c AFM height image 90 min after BIAP addition.

localization [67]. AFM data were recently reported on adsorption of both the anchor-containing and the phospholipase $\mathrm{C}$ solubilized form of the rat osseous plate alkaline phosphatase at the surface of LB films made of dimyristoylphosphatidic acid [17]. Although there are no negatively charged phospholipids at the surface of healthy eukaryotic cells, this suggested that electrostatic interactions could also modulate GPI proteins/membranes interactions.

Direct visualization of AP-GPI dimers and aggregates inserted in membrane domains was reported both for samples where the protein was added after the SLBs formation $\left(\mathrm{SLB}_{\mathrm{a}} \mathrm{s}\right)$ and for samples in which the protein was inserted during the formation of the liposomes $\left(\mathrm{SLB}_{\mathrm{b}} \mathrm{s}\right)$, before the SLBs formation by fusion of the proteincontaining vesicles $[18,40,68,82]$. Two categories of SLBs under fluid-ordered phase separation have been examined by AFM. The first consisted of fluid $\left(l_{\mathrm{d}}\right)$-gel phases binary mixtures. The second regrouped ternary mixtures of composition closer to that expected for rafts microdomains, with $l_{\mathrm{o}}-l_{\mathrm{d}}$ or $\left(\mathrm{gel} / l_{\mathrm{o}}\right)-l_{\mathrm{d}}$ domains coexistence assumed to take place, according to the phase diagrams of vesicles [22, 89].

\section{Interaction of AP-GPI with ordered gel domains}

Starting with fluid $\left(l_{\mathrm{d}}\right)$-gel phases binary mixtures, $\mathrm{SLB}_{\mathrm{a}} \mathrm{s}$ experiments with BIAP were done, besides DOPC/DPPC (1:1 mol:mol), on DOPC/bovine brain sphingomyelin (SM) (DOPC/SM, 1:1 mol:mol) and palmitoyloleoylphosphatidylcholine (POPC)/SM (POPC/SM, 1:1 mol:mol). POPC is a major natural phosphatidylcholine species of biomembranes containing one $\mathrm{C} \mathrm{16:0}$ and one $\mathrm{C}$ 18:1 acyl chains. Accordingly, this last mixture is the most physiologically relevant [38]. For all samples, AFM showed that BIAP spontaneously inserted in the gel, i.e. highly ordered, phase of bilayers [67, 68, 40]. This spontaneous BIAP insertion into SLBs was in accordance with the observations reported for the insertion of various GPI proteins into biomembranes (see above). However, it contrasted with the results obtained on Langmuir monolayers: for films made of pure phosphatidylcholine (PC) species, the penetration process of the GPI anchor into the hydrophobic core from an aqueous phase only occurred at surface pressures lower than $15-22 \mathrm{mN} \mathrm{m}^{-1}[55,79]$, significantly below the $35 \mathrm{mN} \mathrm{m}^{-1}$ value estimated for biomembranes [23]. The absence of phase separation in Langmuir monolayers experiments might account for the apparent discrepancy between the results. The presence of both line tension between the fluid and ordered domains and packing defects or local heterogeneity in the ordered domains [36, 14] likely favors BIAP insertion in both SLBs and biomembranes [75]. Figure 2 is in good accordance with this hypothesis: time dependent experiments showed that the first BIAP dimers were detected at the border of the fluidgel domains. In addition, BIAP was found to preferentially interact with pure DPPC SLBs made by LB deposition at $40 \mathrm{mN} \mathrm{m}^{-1}$ and presenting defects [21]. The second original information provided by AFM analysis of these samples, through the direct determination of domains area, was that BIAP insertion was associated with a net transfer of phospholipids between fluid and gel domains. The same series of experiments strongly suggested that BIAP interacted with the most ordered lipid species in samples presenting gel-gel phase separation. The direction of the phospholipids net transfer either from the fluid to the gel phase or the opposite most likely depended in part on the matching between the hydrophobic thickness of the BIAP acyl chains and the phospholipids constituting the two phases. It was also affected by the gradient of lipid order at the interface of the fluid and gel phases. To summarize, these data strongly suggested that the GPI anchor might contribute to the formation of its most appropriate membrane environment in terms of hydrophobic length and lipid order parameter [40]. Like for BIAP, PLAP has been visualized in the gel SM enriched ordered phase in $\mathrm{SLB}_{\mathrm{b}} \mathrm{S}$ made of DOPC/SM [82]. 


\section{Interaction of AP-GPI with model rafts}

Both types of SLBs have also been used to examine the interactions of AP-GPI with model rafts, i.e. ternary mixtures containing an unsaturated PC, sphingomyelin, and variable concentrations of cholesterol. For PLAP introduced in the liposomes before fusion with the mica $\left(\mathrm{SLB}_{\mathrm{b}} \mathrm{S}\right)$, the protein was visualized practically exclusively $(92 \%)$ in the SM/Chl enriched $l_{\mathrm{o}}$ domains of $\mathrm{DOPC} / \mathrm{SM} /$ Chl (1:1:1, mol:mol) [82]. A similar conclusion was reached for BIAP inserted in $l_{\mathrm{o}}$ domains of DOPC/SM/ Chl (1:1:0.35, mol:mol) SLB ${ }_{a}$ s [68]. The presence of Chl in the lipid mixture was shown to markedly increase the quantitative insertion of BIAP. It also resulted in a homogeneous distribution of protein dimers in the ordered domains. Such homogeneous protein distribution was in accordance with the existence of a lateral diffusion only modestly reduced in $l_{\mathrm{o}}$ phase as compared to the $l_{\mathrm{d}}$ phase [2]. This effect of $\mathrm{Chl}$ in enhancing the insertion of BIAP, which also resulted in an increase of the ordered domains size, was further demonstrated by adding Chl-loaded methyl- $\beta$-cyclodextrin complexes to DOPC/SM bilayers incubated with the protein [68]. As mentioned earlier, $\mathrm{POPC} / \mathrm{SM} / \mathrm{Chl}$ ternary mixtures are more relevant to the composition of biomembrane domains than DOPC/SM/Chl. Recent experiments on BIAP interaction with $\mathrm{SLB}_{\mathrm{a}} \mathrm{s}$ made of POPC/SM/Chl (1:1:0.35, mol:mol) have shown that, at room temperature, the spontaneously inserted protein was essentially, if not exclusively, visualized in the $l_{\mathrm{o}}\left(\mathrm{gel} / l_{\mathrm{o}}\right)$ ordered domains of the bilayer [39]. Time-dependent temperature experiment, however, demonstrated that this distribution of proteins, in the ordered phases for temperatures below $\sim 30^{\circ} \mathrm{C}$, was altered at higher temperatures. For a temperature range between $\sim 30$ and $40^{\circ} \mathrm{C}$, including the physiological temperature, BIAP was visualized both in the $l_{\mathrm{o}}$ and $l_{\mathrm{d}}$ phases (Fig. 3). Few small smooth domains devoid of BIAP were also observed in the $l_{\mathrm{d}}$ phase. According to the data obtained earlier on binary gel $/ l_{\mathrm{d}}$ bilayers, redistri-
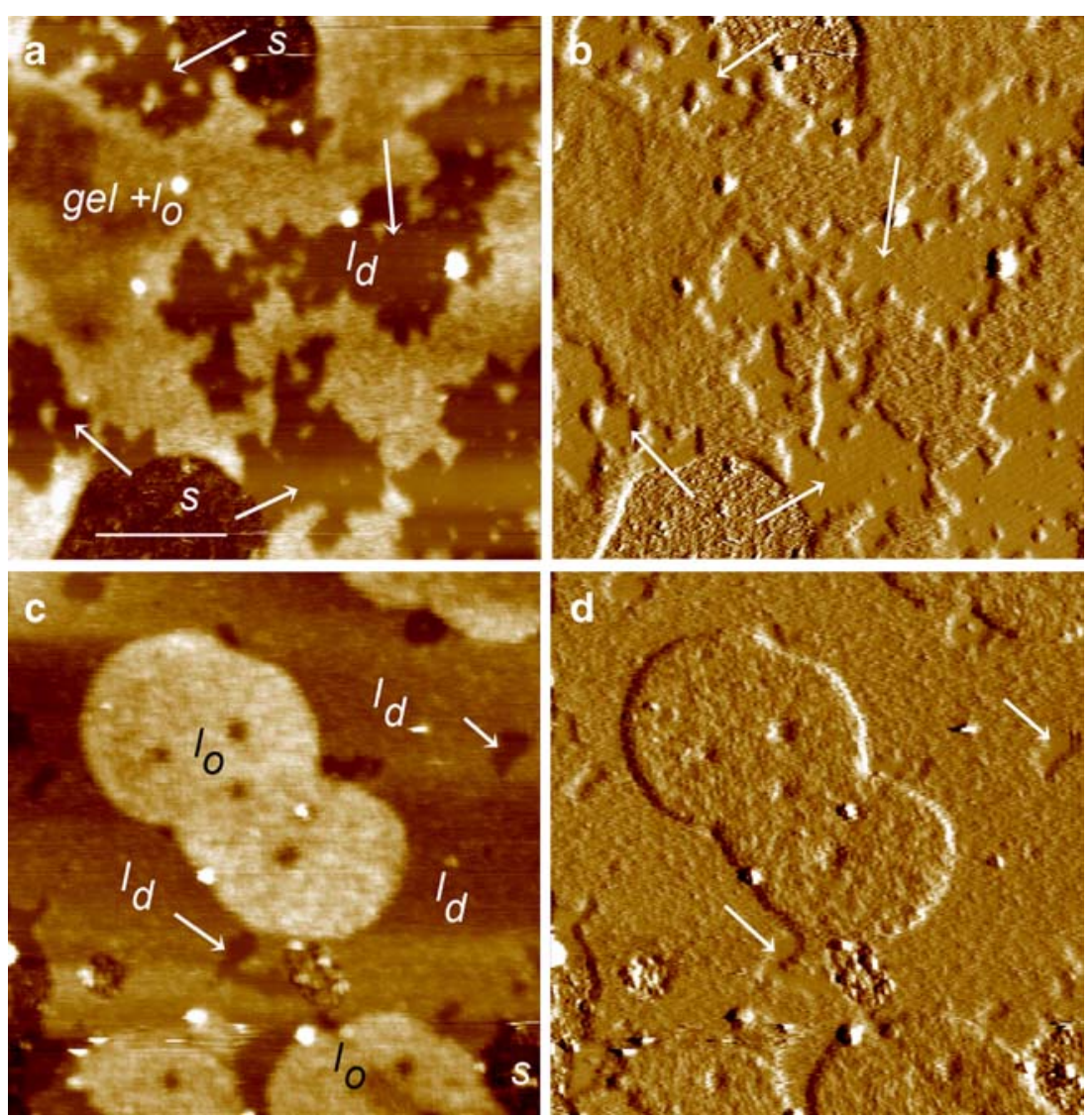

Fig. 3 BIAP inserted in model rafts redistributes between domains as a function of temperature. Supported bilayers made of POPC/SM/Ch1 (1:1:0.35 mol:mol) preincubated with BIAP were imaged in phosphate buffered saline (PBS), $\mathrm{pH} 7.4$, at $2^{\circ} \mathrm{C}(\mathbf{a}$ and $\mathbf{b})$ and $35^{\circ} \mathrm{C}$ (c and $\mathbf{d}$ ). Images $\mathbf{a}$ and $\mathbf{c}$ are height images while $\mathbf{b}$ and $\mathbf{d}$ are the corresponding deflection images, respectively. Roughness of the sample surface is more easily visualized using these deflection images. At low

temperature, BIAP is essentially in the ordered domains (gel $+l_{\mathrm{o}}$ ), the fluid domains $\left(l_{\mathrm{d}}\right)$ appearing smooth (white arrows). At $35^{\circ} \mathrm{C}$ both ordered $\left(l_{\mathrm{o}}\right)$ and fluid $\left(l_{\mathrm{d}}\right)$ domains are covered with BIAP with the exception of a few small domains present in the fluid phase (arrows). Bar $1 \mu \mathrm{M}$; vertical color scale: $25 \mathrm{~nm} ; s$ is the mica substrate noncovered by the bilayer. For further details see the work of Giocondi et al. [39] 
bution of BIAP between $\left(\mathrm{gel} / l_{\mathrm{o}}\right)$ ordered and $l_{\mathrm{d}}$ fluid phases strongly suggested that the lipid order gradient between phases was reduced upon increasing the temperature. This could be due to the presence of a higher Chl concentration in the membrane fluid phase which would agree with the recently reported decrease in the affinity of $\mathrm{Chl}$ to $\mathrm{SM}$ relative to POPC when raising the temperature [88]. On the other hand, existence of small smooth domains without BIAP in the fluid phase strongly suggests that Chl and SM molecules were not totally homogeneously distributed in the "fluid" phase.

AFM visualization of BIAP in the fluid phase of model rafts established the redistribution of a GPI-anchored protein between ordered and fluid domains as a function of temperature. This visualization also demonstrated that the presence of AP-GPI in the fluid $l_{\mathrm{d}}$ phase could be shown by AFM, at least under experimental conditions where a large amount of proteins was incorporated in the samples. Moreover, the relative height of the protein above the bilayer interface, which is function of its packing in the membrane, was about two times less on the fluid than on the ordered phase. This strongly suggested that even at the higher temperature where the lateral diffusion is the highest, the percentage of BIAP in the fluid phase remained significantly lower than in the gel phase, a normal situation for a raft marker. These results differ from those recently obtained with PLAP in which, using $\mathrm{SLB}_{\mathrm{b}} \mathrm{s}$, only one-fourth of the total AP-GPI was found, with significant aggregation, in the $l_{\mathrm{o}}$ domains at room temperature [18]. The conclusions of this last paper, in which fluorescence correlation spectroscopy and confocal fluorescence were also used, also differ from the previous one on PLAP [82]. They were however close to those obtained by the same group on GUVs using fluorescence markers [52]. Keeping in mind that PLAP was found to be 95 and $99 \%$ detergent-insoluble at the plasma membrane [10] and in model rafts liposomes [84], respectively, these data raise interesting questions on the different results on PLAP, the difference between PLAP and BIAP behaviors and the respective information provided by fluorescence and AFM.

First, concerning the apparent variability in PLAP results, it is worth noting that brain-SM rather than synthetic stearoyl-SM was used in the initial experiments. As discussed above, this is a first parameter which could alter the AP-GPI partition between ordered and fluid phases. Besides the presence of fluorescent probes whose effect on phase boundaries cannot be excluded, even for concentrations as low as $0.01 \%$ [90], there are other parameters to consider. For example, the different procedures followed to insert PLAP in the bilayers and the control of PLAP sidedness, first in the vesicles [73, 92], then in the $\mathrm{SLB}_{\mathrm{b}} \mathrm{S}$ could affect the results. This also applies to the behaviour of PLAP eventually present in the $\mathrm{SLB}_{\mathrm{b}} \mathrm{S}$ proximal monolayer that faced the mica. The interaction between the proximal leaflet and the support distant of $\sim 2$ $3 \mathrm{~nm}$ in buffer $[35,50]$ is enhanced by adding calcium to the buffer [5]. In what concerns BIAP, for which spontaneous insertion insured an exclusive protein orientation on the distal leaflet, its preferential distribution in the most ordered phases of the mixtures tested was most likely a consequence of the hydrophobic anchor composition. BIAP contains only fatty acid esters, with a remarkably high content of octadecanoate and hexadecanoate saturated fatty acids. Moreover, a significant fraction of the GPI anchor contains an additional long-chain fatty acid, possibly inositol-linked [13]. On the other hand, the GPI membrane anchor of human PLAP is made of 1-O-alkyl-2-O-acylglycerol that contains a significant amount of unsaturated $C$ 18:1 [77], i.e. is less ordered than the intestinal enzyme.

It has been proposed that the underestimate of the PLAP present in the fluid phase was due to the slow speed of the AFM images acquisition and the higher diffusion coefficient in this phase [18]. This certainly limits the accuracy of the determination of a partition coefficient. However, the two to five times difference in $l_{\mathrm{d}}$ vs $l_{\mathrm{o}}$ lateral diffusion coefficients $[2,52]$ can hardly explain alone the discrepancies between PLAP results, taking into account the various scan rates and scan sizes between the different experiments. Part of the answer is perhaps contained in the data presented in Fig. 4 showing a temperature-dependent experiment with a low amount of inserted BIAP. AFM images of the $\mathrm{SLB}_{\mathrm{a}}$ at $18^{\circ} \mathrm{C}$ (Fig. 4a) revealed three different levels, that should correspond from the lower to the higher, to $l_{\mathrm{d}}, l_{\mathrm{o}}$, and gel phases, with a limited amount of BIAP inserted in this most ordered phase. Upon heating, the gel phase first decreased in size (Fig. 4b), then disappeared (Fig. 4c), and BIAP could not be any longer localized either in the $l_{\mathrm{o}}$ or in the $l_{\mathrm{d}}$ phases. This is in contrast with what was previously reported for high protein concentrations. Such an observation supported the view that the high diffusion coefficients in the liquid phases can limit the possibility to image proteins [18] when they are present in low amounts. Finally, differences between fluorescence and AFM data might be related to the pronounced effect of scanning forces on AP-GPI visualization. As recently reported [40], the use of scanning forces higher than $300 \mathrm{pN}$ resulted in the extraction of a large number of BIAP molecules from the ordered domains (Fig. 5). Such an effect is in accordance with the low forces required to extract phospholipids $[30,58]$, the recovering protein anchored to the membrane via a myristic acid [24] and BIAP [21] from a bilayer. The extraction force required might also differ between fluid and ordered phases and, in our experience, could occur in both contact and oscillating modes. 


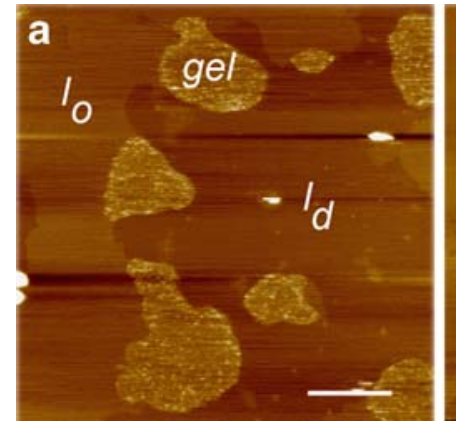

Fig. 4 AFM does not allow to image BIAP in fluid domains when present in limited amounts. Supported bilayers made of POPC/SM/Chl (1:1:0.35 mol:mol) were preincubated with BIAP and imaged in phosphate buffered saline (PBS), $\mathrm{pH}$ 7.4. In this experiment, the amount of BIAP incorporated in the bilayer was much lower than in

\section{Strengths and weaknesses of AFM in the study of AP-GPI-membrane domains interactions}

To conclude this part, the example of AP-GPI [9] illustrates well the strengths and weaknesses of AFM. By giving direct access to the imaging of proteins in membrane domains, the AFM studies have demonstrated that BIAP spontaneously inserted in ordered domains of phaseseparated membranes and that this insertion could be associated with a net transfer of lipids whose direction depends on the lipid order gradient. They have also shown that the protein partition between fluid and ordered membrane phases is affected by temperature. This reinforces the questioning about the physiological relevance of DRMs prepared at low temperature [61]. The results also strongly suggest that the length and the degree of saturation of the hydrophobic part of the GPI anchor play a crucial role on the distribution of GPI proteins between fluid and ordered membranes domains. In accordance with this hypothesis, a recent AFM study using model rafts made with sphingomyelin of various chain lengths demonstrates that acyl chain length hydrophobic mismatch influences the distribution of a GPIanchored form of angiotensin converting enzyme and membrane dipeptidase GPI proteins between fluid and ordered domains [34]. On the other hand, the time required to acquire one image ( $\sim 1-5$ min for commercial equipments) actually precludes the quantitative determination of fluid-ordered partition coefficient for diluted, rapidly diffusing molecules. New high-speed AFM equipment [3, 46] should overcome this limit.

\section{Predictable consequences for biomembranes}

Analysis of the lipid anchor reveals large variations in the composition and linkages of the diacyl- or alkyl-acylglycerol moiety of GPI proteins [31, 62, 63]. For instance, the saturated acyl chains of variant surface glycoprotein VSG, Thy-1, renal membrane dipeptidase, and human folate binding protein contain 14, 16, 18, and 22 carbons, respectively $[9,62,63]$. As pointed out in a recent review, we still know very little concerning the structures of side chains and lipid moieties on the large number of GPI proteins [66]. Protein-specific GPI anchors have been described within Saccharomyces cerevisiae [31]. Furthermore, recent data strongly suggest they could also play a determinant role in mammalian cells in the distribution of GPI proteins between subset of microdomains [72]. Fatty acid remodeling of the GPI anchors, required for their association with membrane ordered domains [45, 65], could be part of the process leading to the synthesis of these specific anchors. In accordance with this view, the differen-
Fig. 5 Using too large scanning forces extracts BIAP from the bilayer. Successive scans of the same zone demonstrating the effects of too large scanning forces on the imaging of BIAP. Bars correspond to $1 \mu \mathrm{m}$ for a and $500 \mathrm{~nm}$ for $\mathbf{b}$ and $\mathbf{c}$. Vertical scale $10 \mathrm{~nm}$. For further details see the work of Giocondi et al. [40]
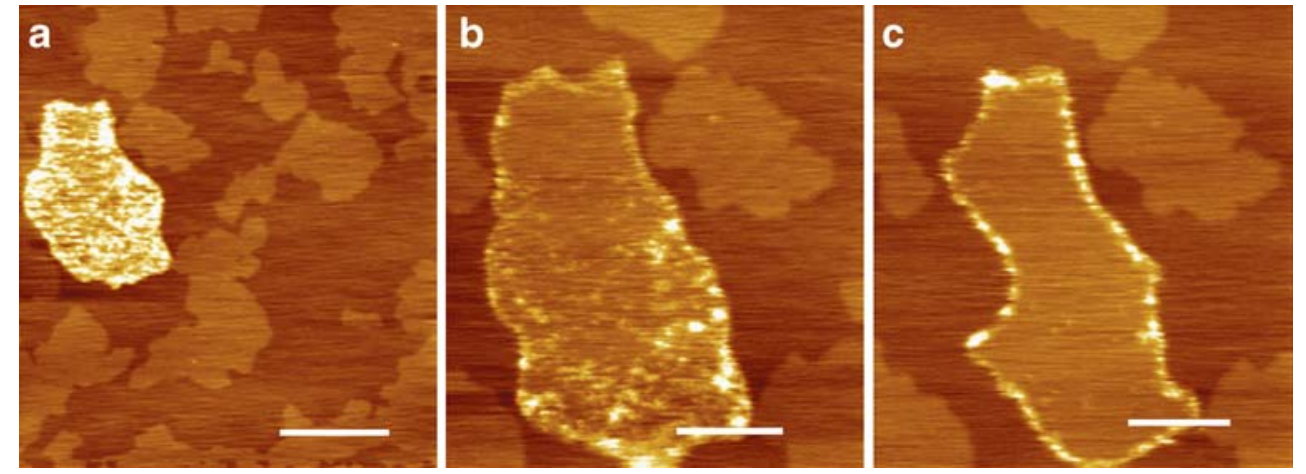
tial insolubility of various GPI proteins into various nonionic detergents [86] suggests that different GPI proteins localize in different categories of microdomains. In the same line, it was reported that functionally different GPI proteins are organized in different domains on the neuronal surface [64] as well as on the surface of CHO cells [94]. Similarly, two recombinant GPI-anchored green fluorescent proteins that differ in their GPI anchor have distinct membrane microdomain localization [59]. In cells, distinct lipid microdomains were also characterized on the basis of their relative enrichment in $\mathrm{GM}_{1}$ and $\mathrm{GM}_{3}$ gangliosides [41, 49]. AFM as well as fluorescence experiments on GUV have demonstrated that simple binary or ternary mixtures containing natural SM can adopt different shapes [4] and eventually undergo gel-gel phase separation [40, 37], a property linked to the large difference in the length of their constitutive acyl chains. Taken together, these data strongly suggest that, within a membrane, subclasses of different GPI proteins can colocalize in subsets of microdomains enriched in sphingolipids and cholesterol. The length and lipid order of the GPI anchor are one of the determinant properties of the GPI protein subclasses. GPI protein behavior and partition coefficient between fluid and ordered domains would then be function of the GPI subclasses they belong to. AFM and fluorescence experiments on model membranes made of lipids of variable compositions and containing simultaneously different GPI proteins would certainly provide a better understanding of biomembranes organization.

\section{References}

1. Ahmed SN, Brown DA, London E (1997) On the origin of sphingolipid/cholesterol-rich detergent-insoluble cell membranes: physiological concentrations of cholesterol and sphingolipid induce formation of a detergent-insoluble, liquid-ordered lipid phase in model membranes. Biochemistry 36:10944-10953

2. Almeida PF, Vaz WL, Thompson TE (1992) Lateral diffusion and percolation in two-phase, two-component lipid bilayers. Topology of the solid-phase domains in-plane and across the lipid bilayer. Biochemistry 31:7198-7210

3. Ando T, Kodera N, Takai E, Maruyama D, Saito K, Toda A (2001) A high-speed atomic force microscope for studying biological macromolecules. Proc Natl Acad Sci U S A 98:12468-12472

4. Baumgart T, Hess ST, Webb WW (2003) Imaging coexisting fluid domains in biomembrane models coupling curvature and line tension. Nature 425:821-824

5. Berquand A, Levy D, Gubellini F, Le Grimellec C, Milhiet PE (2007) Influence of calcium on direct incorporation of membrane proteins into in-plane lipid bilayer. Ultramicroscopy 107:928-933

6. Booth AG, Kenny AJ (1974) A rapid method for the preparation of microvilli from rabbit kidney. Biochem J 142:575-581

7. Brasitus TA, Schachter D (1980) Lipid dynamics and lipid-protein interactions in rat enterocyte basolateral and microvillus membranes. Biochemistry 19:2763-2769

8. Brasitus TA, Tall AR, Schachter D (1980) Thermotropic transitions in rat intestinal plasma membranes studied by differential scanning calorimetry and fluorescence polarization. Biochemistry 19:1256-1261

9. Brewis IA, Ferguson MA, Mehlert A, Turner AJ, Hooper NM (1995) Structures of the glycosyl-phosphatidylinositol anchors of porcine and human renal membrane dipeptidase. Comprehensive structural studies on the porcine anchor and interspecies comparison of the glycan core structures. J Biol Chem 270:22946-22956

10. Brown DA, Rose JK (1992) Sorting of GPI-anchored proteins to glycolipid-enriched membrane subdomains during transport to the apical cell surface. Cell 68:533-544

11. Brown D, Waneck GL (1992) Glycosyl-phosphatidylinositolanchored membrane proteins. J Am Soc Nephrol 3:895-906

12. Brown DA, London E (1997) Structure of detergent-resistant membrane domains: does phase separation occur in biological membranes. Biochem Biophys Res Commun 240:1-7

13. Bublitz R, Armesto J, Hoffmann-Blume E, Schulze M, Rhode H, Horn A, Aulwurm S, Hannappel E, Fischer W (1993) Heterogeneity of glycosylphosphatidylinositol-anchored alkaline phosphatase of calf intestine. Eur J Biochem 217:199-207

14. Burns AR, Frankel DJ, Buranda T (2005) Local mobility in lipid domains of supported bilayers characterized by atomic force microscopy and fluorescence correlation spectroscopy. Biophys J 89:1081-1093

15. Camolezi FL, Daghastanli KR, Magalhaes PP, Pizauro JM, Ciancaglini P (2002) Construction of an alkaline phosphataseliposome system: a tool for biomineralization study. Int J Biochem Cell Biol 34:1091-1101

16. Carmel G, Rodrigue F, Carriere S, Le Grimellec C (1985) Composition and physical properties of lipids from plasma membranes of dog kidney. Biochim Biophys Acta 818:149-157

17. Caseli L, Masui D, Prazeres Melo Furriel R, Assis Leone F, Darbello Zaniquelli M (2007) Influence of the glycosylphosphatidylinositol anchor in the morphology and roughness of LangmuirBlodgett films of phospholipids containing alkaline phosphatases. Thin Solid Films 515:4801-4807

18. Chiantia S, Ries J, Kahya N, Schwille P (2006) Combined AFM and two-focus SFCS study of Raft-exhibiting model membranes. ChemPhysChem 7:2409-2418

19. Civenni G, Test ST, Brodbeck U, Butikofer P (1998) In vitro incorporation of GPI-anchored proteins into human erythrocytes and their fate in the membrane. Blood 91:1784-1792

20. Connell SD, Smith DA (2006) The atomic force microscope as a tool for studying phase separation in lipid membranes. Mol Membr Biol 23:17-28

21. Cross B, Ronzon F, Roux B, Rieu JP (2005) Measurement of the anchorage force between GPI-anchored alkaline phosphatase and supported membranes by AFM force spectroscopy. Langmuir 21:5149-5153

22. de Almeida RF, Fedorov A, Prieto M (2003) Sphingomyelin/ phosphatidylcholine/cholesterol phase diagram: boundaries and composition of lipid rafts. Biophys J 85:2406-2416

23. Demel RA, Geurts van Kessel WS, Zwaal RF, Roelofsen B, van Deenen LL (1975) Relation between various phospholipase actions on human red cell membranes and the interfacial phospholipid pressure in monolayers. Biochim Biophys Acta 406:97-107

24. Desmeules P, Grandbois M, Bondarenko VA, Yamazaki A, Salesse C (2002) Measurement of membrane binding between recoverin, a calcium-myristoyl switch protein, and lipid bilayers by AFM-based force spectroscopy. Biophys J 82:3343-3350

25. Douglas AP, Kerley R, Isselbacher KJ (1972) Preparation and characterization of the lateral and basal plasma membranes of the rat intestinal epithelial cell. Biochem J 128:1329-1338

26. Dufrene YF, Lee GU (2000) Advances in the characterization of supported lipid films with the atomic force microscope. Biochim Biophys Acta 1509:14-41 
27. Dykstra ML, Cherukuri A, Pierce SK (2001) Floating the raft hypothesis for immune receptors: Access to rafts controls receptor signaling and trafficking. Traffic 2:160-166

28. Eichholz A, Crane RK (1974) Isolation of plasma membranes from intestinal brush borders. Methods Enzymol 31:123-134

29. Engel A, Muller DJ (2000) Observing single biomolecules at work with the atomic force microscope. Nat Struct Biol 7:715-718

30. Evans E, Ludwig F (2000) Dynamic strengths of molecular anchoring and material cohesion in fluid biomembranes. J Phys Condens Matter 12:A315-A320

31. Fankhauser C, Homans SW, Thomas-Oates JE, McConville MJ, Desponds C, Conzelmann A, Ferguson MA (1993) Structures of glycosylphosphatidylinositol membrane anchors from Saccharomyces cerevisiae. J Biol Chem 268:26365-26374

32. Ferguson MA (1999) The structure, biosynthesis and functions of glycosylphosphatidylinositol anchors, and the contribution of trypanosome research. J. Cell Sci 112:2799-2809

33. Forstner GG, Tanaka K, Isselbacher KJ (1968) Lipid composition of the isolated rat intestinal microvillus membrane. Biochem J 109:51-59

34. Garner AE, Smith DA, Hooper NM (2007) Sphingomyelin chain length influences the distribution of GPI-anchored proteins in rafts in supported lipid bilayers. Mol Membr Biol 24:233-242

35. Giocondi MC, Le Grimellec C (2004) Temperature dependence of the surface topography in dimyristoylphosphatidylcholine/ distearoylphosphatidylcholine multibilayers. Biophys J 86:22182230

36. Giocondi MC, Pacheco L, Milhiet PE, Le Grimellec C (2001) Temperature dependence of the topology of supported dimirystoyldistearoyl phosphatidylcholine bilayers. Ultramicroscopy 86: $151-157$

37. Giocondi MC, Boichot S, Plenat T, Le Grimellec CC (2004) Structural diversity of sphingomyelin microdomains. Ultramicroscopy 100:135-143

38. Giocondi MC, Milhiet PE, Dosset P, Le Grimellec C (2004) Use of cyclodextrin for AFM monitoring of model raft formation. Biophys J 86:861-869

39. Giocondi M-C, Besson F, Dosset P, Milhiet P-E, Le Grimellec C (2007) Temperature-dependent localization of GPI-anchored intestinal alkaline phosphatase in model rafts. J Mol Recognit (in press)

40. Giocondi MC, Besson F, Dosset P, Milhiet PE, Le Grimellec C (2007) Remodeling of ordered membrane domains by GPIanchored intestinal alkaline phosphatase. Langmuir 23:9358-9364

41. Gomez-Mouton C, Abad JL, Mira E, Lacalle RA, Gallardo E, Jimenez-Baranda S, Illa I, Bernad A, Manes S, Martinez AC (2001) Segregation of leading-edge and uropod components into specific lipid rafts during $\mathrm{T}$ cell polarization. Proc Natl Acad Sci U S A 98:9642-9647

42. Hancock JF (2006) Lipid rafts: contentious only from simplistic standpoints. Nat Rev Mol Cell Biol 7:456-462

43. Hanzal-Bayer MF, Hancock JF (2007) Lipid rafts and membrane traffic. FEBS Lett 581:2098-2104

44. Hooper NM, Turner AJ (1988) Ectoenzymes of the kidney microvillar membrane. Biochem J 250:865-869

45. Houjou T, Hayakawa J, Watanabe R, Tashima Y, Maeda Y, Kinoshita T, Taguchi R (2007) Changes in molecular species profiles of glycosylphosphatidylinositol anchor precursors in early stages of biosynthesis. J Lipid Res 48:1599-1606

46. Humphris A, Miles M, Hobbs J (2005) A mechanical microscope: high-speed atomic force microscopy. Appl Phys Lett 86:(034106) 034101-034103

47. Ipsen JH, Karlstrom G, Mouritsen OG, Wennerstrom H, Zuckermann MJ (1987) Phase equilibria in the phosphatidylcholinecholesterol system. Biochim Biophys Acta 905:162-172

48. Jacobson K, Mouritsen OG, Anderson RG (2007) Lipid rafts: at a crossroad between cell biology and physics. Nat Cell Biol 9:7-14
49. Janich P, Corbeil D (2007) GM1 and GM3 gangliosides highlight distinct lipid microdomains within the apical domain of epithelial cells. FEBS Lett 581:1783-1787

50. Johnson SJ, Bayerl TM, McDermott DC, Adam GW, Rennie AR, Thomas RK, Sackmann E (1991) Structure of an adsorbed dimyristoylphosphatidylcholine bilayer measured with specular reflection of neutrons. Biophys J 59:289-294

51. Johnston LJ (2007) Nanoscale imaging of domains in supported lipid membranes. Langmuir 23:5886-5895

52. Kahya N, Brown DA, Schwille P (2005) Raft partitioning and dynamic behavior of human placental alkaline phosphatase in giant unilamellar vesicles. Biochemistry 44:7479-7489

53. Karnovsky MJ, Kleinfeld AM, Hoover RL, Klausner RD (1982) The concept of lipid domains in membranes. J Cell Biol 94:1-6

54. Kihn L, Rutkowski D, Stinson RA (1990) Incorporation of human liver and placental alkaline phosphatases into liposomes and membranes is via phosphatidylinositol. Biochem Cell Biol 68:1112 1118

55. Kouzayha A, Besson F (2005) GPI-alkaline phosphatase insertion into phosphatidylcholine monolayers: phase behavior and morphology changes. Biochem Biophys Res Commun 333:1315-1321

56. Le Du MH, Stigbrand T, Taussig MJ, Menez A, Stura EA (2001) Crystal structure of alkaline phosphatase from human placenta at 1.8 A resolution. Implication for a substrate specificity. J Biol Chem 276:9158-9165

57. Le Grimellec C, Giocondi MC, Carriere B, Carriere S, Cardinal J (1982) Membrane fluidity and enzyme activities in brush border and basolateral membranes of the dog kidney. Am J Physiol 242: F246-F253

58. Leckband D, Muller W, Schmitt FJ, Ringsdorf H (1995) Molecular mechanisms determining the strength of receptormediated intermembrane adhesion. Biophys J 69:1162-1169

59. Legler DF, Doucey MA, Schneider P, Chapatte L, Bender FC, Bron C (2005) Differential insertion of GPI-anchored GFPs into lipid rafts of live cells. Faseb J 19:73-75

60. Levi M, Molitoris BA, Burke TJ, Schrier RW, Simon FR (1987) Effects of vitamin D-induced chronic hypercalcemia on rat renal cortical plasma membranes and mitochondria. Am J Physiol 252: F267-275

61. Lichtenberg D, Goni FM, Heerklotz H (2005) Detergent-resistant membranes should not be identified with membrane rafts. Trends Biochem Sci 30:430-436

62. Low MG (1989) The glycosyl-phosphatidylinositol anchor of membrane proteins. Biochim Biophys Acta 988:427-454

63. Luhrs CA, Slomiany BL (1989) A human membrane-associated folate binding protein is anchored by a glycosyl-phosphatidylinositol tail. J Biol Chem 264:21446-21449

64. Madore N, Smith KL, Graham CH, Jen A, Brady K, Hall S, Morris R (1999) Functionally different GPI proteins are organized in different domains on the neuronal surface. Embo J 18:6917-6926

65. Maeda Y, Tashima Y, Houjou T, Fujita M, Yoko-o T, Jigami Y, Taguchi R, Kinoshita T (2007) Fatty acid remodeling of GPIanchored proteins is required for their raft association. Mol Biol Cell 18:1497-1506

66. Mayor S, Riezman H (2004) Sorting GPI-anchored proteins. Nat Rev Mol Cell Biol 5:110-120

67. Milhiet P-E, Giocondi M-C, Baghdadi O, Ronzon F, Le Grimellec C, Roux B (2002) AFM Detection of GPI protein insertion into DOPC/ DPPC model membranes. Single Mol 3:135-140

68. Milhiet PE, Giocondi MC, Baghdadi O, Ronzon F, Roux B, Le Grimellec C (2002) Spontaneous insertion and partitioning of alkaline phosphatase into model lipid rafts. Embo Reports 3: 485-490

69. Milhiet PE, Giocondi MC, Le Grimellec C (2003) AFM imaging of lipids domains in model membranes. http://www.thescientificworld. com 3:59-74 
70. Moran P, Beasley H, Gorrell A, Martin E, Gribling P, Fuchs H, Gillett N, Burton LE, Caras IW (1992) Human recombinant soluble decay accelerating factor inhibits complement activation in vitro and in vivo. J Immunol 149:1736-1743

71. Morrisett JD, Pownall HJ, Plumlee RT, Smith LC, Zehner ZE (1975) Multiple thermotropic phase transitions in Escherichia coli membranes and membrane lipids. A comparison of results obtained by nitroxyl stearate paramagnetic resonance, pyrene excimer fluorescence, and enzyme activity measurements. J Biol Chem 250:6969-6976

72. Nicholson TB, Stanners CP (2006) Specific inhibition of GPIanchored protein function by homing and self-association of specific GPI anchors. J Cell Biol 175:647-659

73. Nosjean O, Roux B (1999) Ectoplasmic insertion of a glycosylphosphatidylinositol-anchored protein in glycosphingolipid- and cholesterol-containing phosphatidylcholine vesicles. Eur J Biochem 263:865-870

74. Pike LJ (2006) Rafts defined: a report on the Keystone symposium on lipid rafts and cell function. J Lipid Res 47:1597-1598

75. Pokorny A, Almeida PF, Vaz WL (2001) Association of a fluorescent amphiphile with lipid bilayer vesicles in regions of solid-liquid-disordered phase coexistence. Biophys J 80:1384-1394

76. Premkumar DR, Fukuoka Y, Sevlever D, Brunschwig E, Rosenberry TL, Tykocinski ML, Medof ME (2001) Properties of exogenously added GPI-anchored proteins following their incorporation into cells. J Cell Biochem 82:234-245

77. Redman CA, Thomas-Oates JE, Ogata S, Ikehara Y, Ferguson MA (1994) Structure of the glycosylphosphatidylinositol membrane anchor of human placental alkaline phosphatase. Biochem J 302 (Pt 3):861-865

78. Ronzon F, Desbat B, Buffeteau T, Mingotaud C, Chauvet J-P, Roux B (2002) Structure and orientation of a glycosylphosphatidyl Inositol anchored protein at the air/water interface. J Phys Chem B 106:3307-3315

79. Ronzon F, Desbat B, Chauvet JP, Roux B (2002) Penetration of a GPI-anchored protein into phospholipid monolayers spread at the air/water interface. Colloids Surf B: Biointerfaces 23:365-373

80. Sankaram MB, Thompson TE (1990) Interaction of cholesterol with various glycerophospholipids and sphingomyelin. Biochemistry 29:10670-10675

81. Sankaram MB, Thompson TE (1990) Modulation of phospholipid acyl chain order by cholesterol. A solid-state $2 \mathrm{H}$ nuclear magnetic resonance study. Biochemistry 29:10676-10684

82. Saslowsky DE, Lawrence J, Ren X, Brown DA, Henderson RM, Edwardson JM (2002) Placental alkaline phosphatase is efficiently targeted to rafts in supported lipid bilayers. J Biol Chem 277:26966-26970

83. Scheuring S, Levy D, Rigaud JL (2005) Watching the components of photosynthetic bacterial membranes and their in situ organisation by atomic force microscopy. Biochim Biophys Acta 1712:109-127

84. Schroeder RJ, Ahmed SN, Zhu Y, London E, Brown DA (1998) Cholesterol and sphingolipid enhance the Triton X-100 insolubility of glycosylphosphatidylinositol-anchored proteins by promoting the formation of detergent-insoluble ordered membrane domains. J Biol Chem 273:1150-1157

85. Simons K, Ikonen E (1997) Functional rafts in cell membranes. Nature 387:569-572

86. Solomon KR, Mallory MA, Finberg RW (1998) Determination of the non-ionic detergent insolubility and phosphoprotein associations of glycosylphosphatidylinositol-anchored proteins expressed on T cells. Biochem J 334(Pt 2):325-333

87. Sprong H, van der Sluijs P, van Meer G (2001) How proteins move lipids and lipids move proteins. Nat Rev Mol Cell Biol 2:504-513

88. Tsamaloukas A, Szadkowska H, Heerklotz H (2006) Thermodynamic comparison of the interactions of cholesterol with unsaturated phospholipid and sphingomyelins. Biophys J 90:4479-4487

89. Veatch SL, Keller SL (2005) Miscibility phase diagrams of giant vesicles containing sphingomyelin. Phys Rev Lett 94:148101

90. Veatch SL, Leung SS, Hancock RE, Thewalt JL (2007) Fluorescent probes alter miscibility phase boundaries in ternary vesicles. J Phys Chem B 111:502-504

91. Vié V, van Mau N, Giocondi M-C, Lesniewska E, Goudonnet J-P, Heitz F, Le Grimellec C (2000) Near field microscopy approach to the heterogeneity of artificial and biological membranes. In: J (ed) IOS Press, Ohmsa

92. Villar AV, Alonso A, Paneda C, Varela-Nieto I, Brodbeck U, Goni FM (1999) Towards the in vitro reconstitution of caveolae. Asymmetric incorporation of glycosylphosphatidylinositol (GPI) and gangliosides into liposomal membranes. FEBS Lett 457:71-74

93. Vist MR, Davis JH (1990) Phase equilibria of cholesterol/dipalmitoylphosphatidylcholine mixtures: $2 \mathrm{H}$ nuclear magnetic resonance and differential scanning calorimetry. Biochemistry 29:451-464

94. Wang J, Gunning W, Kelley KM, Ratnam M (2002) Evidence for segregation of heterologous GPI-anchored proteins into separate lipid rafts within the plasma membrane. J Membr Biol 189:35-43

95. White $\mathrm{D}$ (1973) The phospholipid composition of mammalian tissues. In: Ansell G, Hawthorne J, Dawson R (eds) Elsevier, Amsterdam

96. Wilfong RF, Neville DM Jr (1970) The isolation of a brush border membrane fraction from rat kidney. J Biol Chem 245:6106-6112 